\title{
PROSES MANUFAKTUR MESIN GERGAJI KAYU UNTUK PENGRAJIN PALET KAYU
}

\author{
Akhmad Syarief ${ }^{1)}$, Akhmad Maulana Gumai') \\ 1,2Program Studi Teknik Mesin, \\ Fakultas Teknik Universitas Lambung Mangkurat \\ JL. Akhmad Yani Km.36 Banjarbaru, Kalimantan Selatan, 70714 \\ Telp. 0511-4772646, Fax 0511-4772646 \\ E-mail: lanajfc@gmail.com
}

\begin{abstract}
Wood saws are hand machines that small industries need. Almost all work processes through a saw machine with good results. Circular saws are not only used in timber industry, but also in the carbuery industry, by plumbing, construction experts, loggers or gardenists. In any hobby there are wearing it. For manufacturing process of making wood sawing machine in allotment for wooden pallet craftsman. The2formulation4of5the3problem 1in making1this2saw machine is how to manufacture wood saw process for wooden pallet craftsman and howmuch budget cost in manufacturing process of saw machine for wooden pallet craftsman. The components of the saw machine are frame, table mat, bearing, shaft, pulley transmission and $V$ belt, while the tools and machinery used in the manufacturing process are electric welding tools, electric grinding wheels, grinding wheels, lathes, and frais machines.
\end{abstract}

\section{Keywords : Wood Sawing Machine, Wooden Pallet, Manufacturing Process}

\section{PENDAHULUAN}

Kemajuan teknologi yang semakin maju, terutama pada pengrajin kayu yang dulunya menggunakan alat manual dengan tenaga manusia beralih ke gergaji tangan dan sampai sekarang menggunakan mesin gergaji kayu.

Pada saat ini industri-industri dominan melakukan pekerjaan dengan mesin tetapi juga masih banyak sekali indutsri yang menggunakan proses manual. Industri tersebut misalnya industri kecil yang belum memiliki cukup modal untuk membeli mesin-mesin semi otomatis1ataupun mesin otomatis penuh, yang relatif lebih mahal.

Peralatan-peralatan yang digunakan oleh indusrti kecil yaitu, mesin gergaji merupakan peralatan yang cukup penting dan cukup sering digunakan, khususnya industri yang bahan dasarnya dari kayu. Dikarenakan kurangnya modal banyak industri kecil yang membuat sendiri mesin semi otomatis yang sederhana, agar dapat mempermudah pengerjaan dalam produksi.

Berdasarkan data diatas maka diharapkan dapat menunjang permasalahan yang selama ini dihadapi oleh industri kecil, seperti kekurangan fasilitas; meningkatkan efektifitas, produktifitas dan kualitas hasil produksi dan mengurangi beban kerja industri kecil.

\section{Mesin Gergaji Kayu}

Mesin tangan yang perlu dimiliki industri kecil adalah mesin gergaji tangan. Hampir semua proses pekerjaan melalui mesin gergaji dengan hasil yang baik. Gergaji lingkaran tangan bukan hanya digunakan pada industri perkayuan saja, melainkan juga pada industri karoseri, tukang pipa, ahli bangunan, tukang tebang pohon atau penata taman. Dalam hobi pun ada yang memakainya (Budianto, 1995). 


\section{Mesin Bubut}

Mesin bubut adalah mesin perkakas yang memproduksi barang dengan bentuk silindris. Mesin bubut pada umumnya suatu mesin perkakas yang digunakan untuk memotong benda dengan cara diputar dan dikenakan pada pahat namun ada juga mesin bubut yang pahat bubutnya berputar dan benda kerja diam. Bubut sendiri merupakan suatu proses pemakanan benda kerja yang pada umumnya proses sayatannya dilakukan dengan cara memutar benda kerja kemudian dikenakan pada pahat yang digerakkan secara translasi sejajar dengan sumbu putar dari benda kerja. Kecepatan pada mesin bubut dapat diatur sesuai kebutuhan dengan cara mengatur perbandingan roda gigi pada gearbox (Taufiq, 1993).

Kecepatan Putar (speed), selalu dihubungkan dengan sumbu utama (spindel) dan benda kerja. Kecepatan putar dinotasikan sebagai putaran per menit (rotations per minute, rpm). Akan tetapi yang diutamakan dalam proses bubut adalah kecepatan potong (cutting speed atau v) atau kecepatan benda kerja dilalui oleh pahat/keliling benda kerja. Secara sederhana kecepatan potong dapat digambarkan sebagai keliling benda kerja dikalikan dengan kecepatan putar (Widarto dkk, 2008).

$v 4=\frac{\pi d n}{1000} ; m /$ menit

Dimana:

v5 : Kecepatan Potong (m/menit)

d4 : Diameter Benda Kerja $(\mathrm{mm})$

n1 : Putaran Benda Penggerak (putaran/menit)

Kecepatan makan

$v f=f . n ; m / m e n i t$

Dimana:

f8 : Gerak Makan

n9 : Putaran Benda Kerja

Waktu pemotongan5

$v=\frac{l t}{v f} ; m / m e n i t$

Dimana:

lt : Panjang Penggerak Benda Kerja

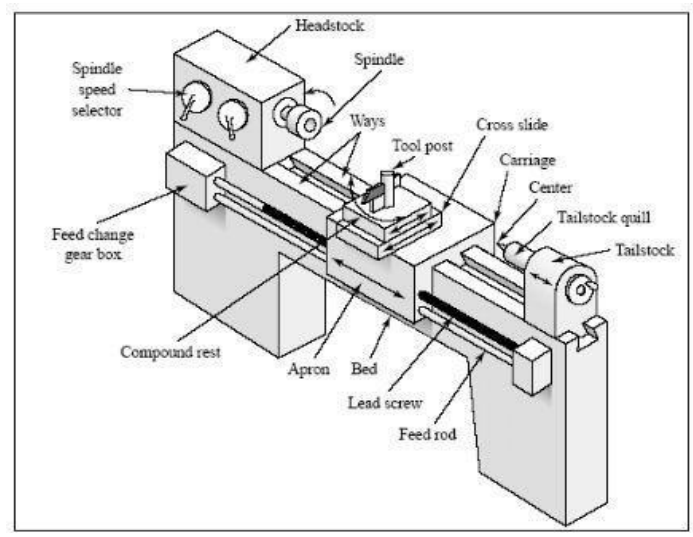

Gambar 1. Skematis Mesin Bubut dan nama bagian-bagiannya

Benda kerja yang berbeda kekerasannya, strukturnya dan kemampuan 
permesinannya diperlukan penentuan cutting speed yang berbeda (Khoir, 2011).

Tabel 1. Kecepatan potong untuk beberapa jenis bahan $(\mathrm{mm} / \mathrm{min})$

\begin{tabular}{|l|l|l|l|l|}
\hline \multirow{2}{*}{ Bahan } & \multicolumn{2}{c|}{ Cutter HSS } & \multicolumn{2}{c|}{ Cutter Karbida } \\
\cline { 2 - 5 } & \multicolumn{1}{|c|}{ Halus } & \multicolumn{1}{c|}{ Kasar } & \multicolumn{1}{c|}{ Halus } & \multicolumn{1}{c|}{ Kasar } \\
\hline Baja Perkakas & $75-100$ & $25-45$ & $185-230$ & $110-140$ \\
\hline Baja Karbon Rendah & $70-90$ & $25-40$ & $170-215$ & $90-120$ \\
\hline Baja Karbon Menengah & $60-85$ & $20-40$ & $40-185$ & $75-110$ \\
\hline Besi Cor Kelabu & $40-45$ & $25-30$ & $110-140$ & $60-75$ \\
\hline Kuningan & $85-110$ & $45-70$ & $185-215$ & $120-150$ \\
\hline Aluminium & $70-110$ & $30-45$ & $140-215$ & $60-90$ \\
\hline
\end{tabular}

\section{Pengelasan}

Pengelasan merupakan bagian penting dari pertumbuhan industri, karena memegang peranan penting dalam bidang konstruksi. Sebagian besar industri modern selalu melibatkan proses pengelasan yang semakin meningkat ditiap tahunnya. Sebagai contoh, dalam industri sarana transportasi, industri perkapalan, industri kereta api, industri kendaraan dan industri konstruksi lainnya, semua industri tersebut membutuhkan sambungan logam berkualitas tinggi.

\section{Las Listrik}

Mengelas artinya menyambung benda-benda kerja logam dengan cara memanasi sampai titik cairnya, di mana pada benda kerja yang mencair atau meleleh akan menyatu dengan bantuan bahan tambahan sehingga terbentuklah suatu sambungan. Melelehnya benda kerja dan bahan tambahan disebabkan oleh panas yang datang dari busur listrik, $v$ busur listrik ini terjadi pada waktu adanya perpindahan arus listrik dari batang elektroda ke benda kerja lewat udara. Busur listrik ini menyala dalam garis lintasan udara yang menyalurkan arus listrik, oleh karena ada tahanan listrik yang tinggi (Daryanto, 1986).

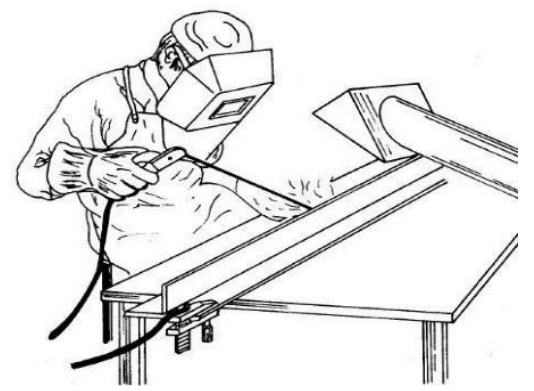

Gambar 2. Pengelasan Mengunakan Las Listrik

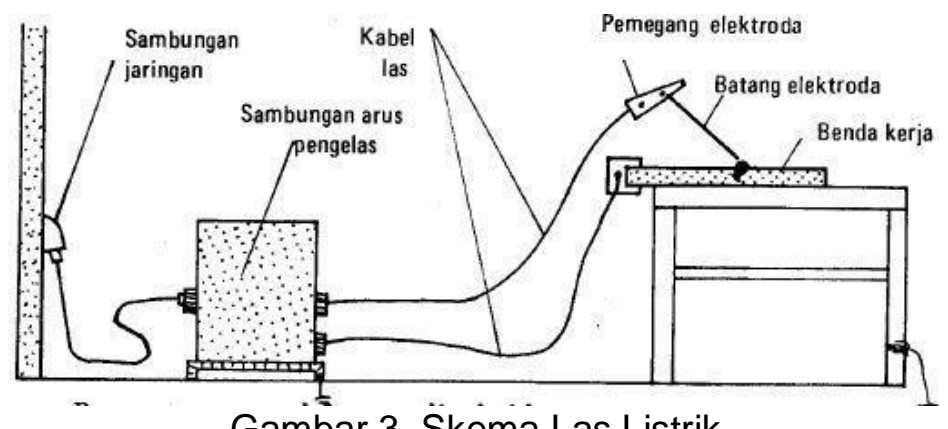

Gambar 3. Skema Las Listrik 


\section{Rangka Kaki}

Jenis rangka yang digunkan adalah besi frofil $L$ dan besi frofil $U$. dimana bahan ini dari segi kekuatan dapat menahan beban dan mudah dalam pembentukan/perakitan.

\section{Bantalan}

Bantalan adalah elemen mesin yang menumpu poros berbeban, sehingga putaran atau gerakan bolak baliknya dapat berlangsung secara halus, aman, dan panjang umur. Bantalan harus cukup kokoh untuk memungkinkan poros serta elemen mesin lainnya bekerja dengan baik. Jika bantalan tidak berfungsi dengan baik maka prestasi seluruh system akan menurun atau tak dapat bekerja secara semestinya (Sularso, 1987. Hal 103).

\section{Poros}

Tujuan dari perencanaan poros adalah untuk menentukan ukuran diameter poros berdasarkan parameter rancang bangun poros dengan menggunakan rumus kekuatan bahan yang ada. Poros yang umumnya meneruskan daya melalui sabuk, roda gigi, dan rantai akan mendapatkan beban puntir dan lentur sehingga pada permukaan poros akan mengalami tegangan geser (Sularso 2004:17).

\section{Transmisi}

Pada mesin gergaji kayu, puli digunakan sebagai transmisi dari putaran poros sebagai penggerak dinamo listrik. Dan untuk komponen ini digunakan sabuk V (V-belt) sebagai alat transmisinya. Sabuk $V$ ini mempunyai gaya gesekan yang agak besar tergantung dari bentuk bajinya, namun disamping itu dapat menghasilkan daya transmisi yang besar yang pada tegangan yang relatif rendah (Gunawan, 2009).

\section{METODE7PENELITIAN}

Alat dan bahan yang digunakan pada proses manufaktur ini, yaitu :

1. Alat
a. Mesin Las SMAW
b. Mesin Gerinda
c. Mesin Bor
d. Mesin Bubut
e. Mesin Frais
f. Gerinda Potong
g. Palu
h. Kikir
i. Kunci 10,12,14

2. Bahan
a. Elektroda LB
b. Dinamo 2HP
c. Pisau Gergaji Kayu 20"
d. Mur dan Baut
e. Besi siku / Profil L
f. Besi Hollow
g. Plat Besi $2 \mathrm{~mm}$
h. Bearing UCP205-16
i. $\quad$ V-Belt A-42
j. Puli 
k. As Poros St 37

I. Cat besi

m. Amplas

Metode proses manufaktur yang dilakukan merupakan langkah awal dalam membangun sebuah alat. Adapun tahapan pembuatan yang dilakukan, yaitu:

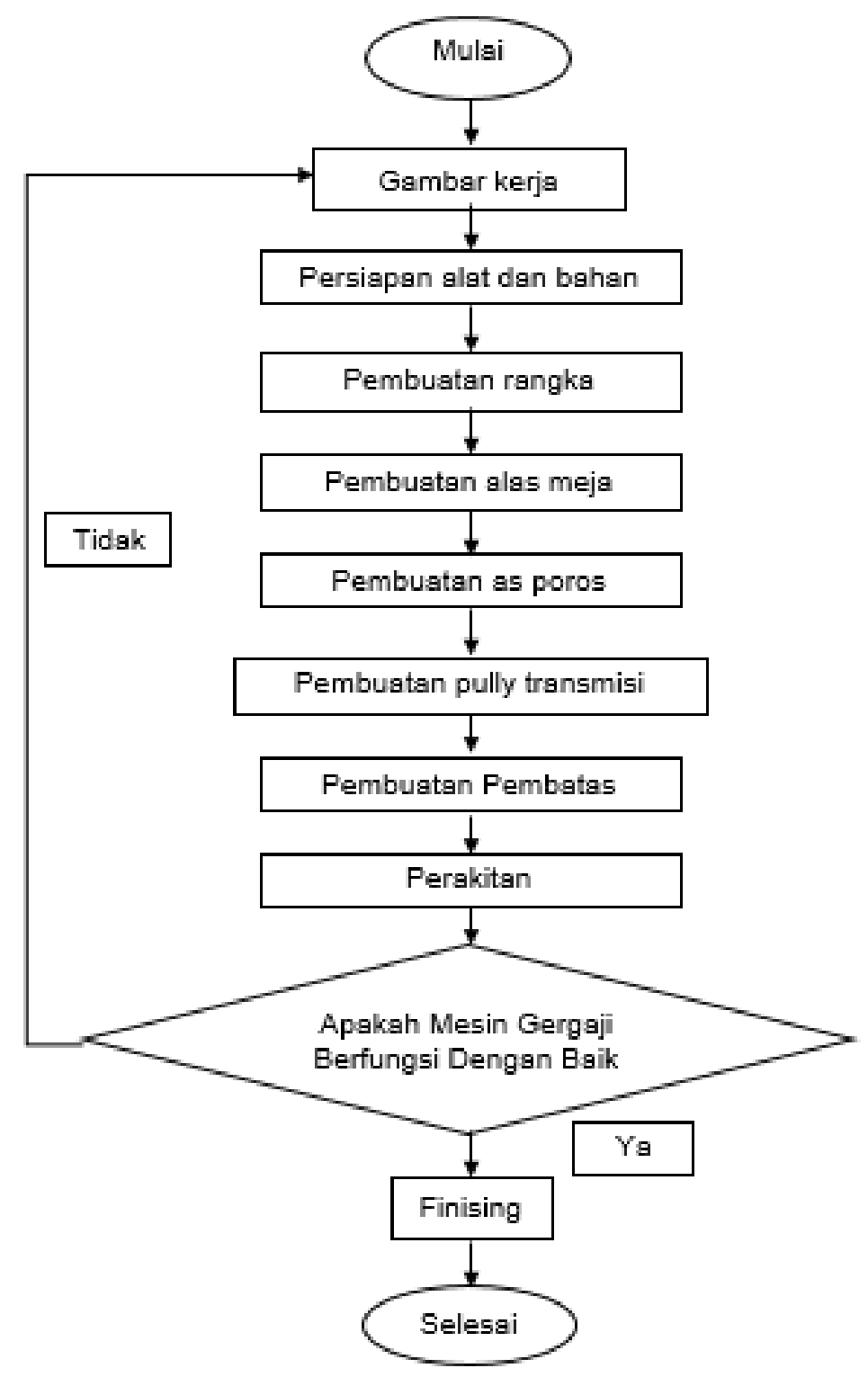

Gambar 4. Metode Proses Manufaktur

\section{HASIL DAN PEMBAHASAN}

Adapun komponen mesin gergaji kayu adalah sebagai berikut:

Rangka Mesin

Rangka mesin terbuat dari bahan besi siku / profil L.

\section{Alas Meja Mesin Gergaji Kayu}

Alas Meja menggunakan plat besi ketebalan $2 \mathrm{~mm}$. 


\section{Poros}

Poros yang di gunakan dalam mesin ini menggunakan bahan besi pejal st37, dimana besi ini cukup kuat untuk menahan daya gergaji kayu.

\section{Transmisi}

Transmisi yang digunakan yaitu puli yang menggunakan bahan besi st37 dan sabuk-v A-42.

\section{Bearing}

Bearing yang digunakan yaitu ball bearing tipe UCP205-16.

\section{Pembatas}

Pembatas yang di menggunakan bahan besi hollow, plat besi, dan baut.

Dengan demikian dapat disusun matriks morfologi mesin gergaji kayu, yang di tunjukan pada Tabel 2.

Tabel 2. Matriks morfologi

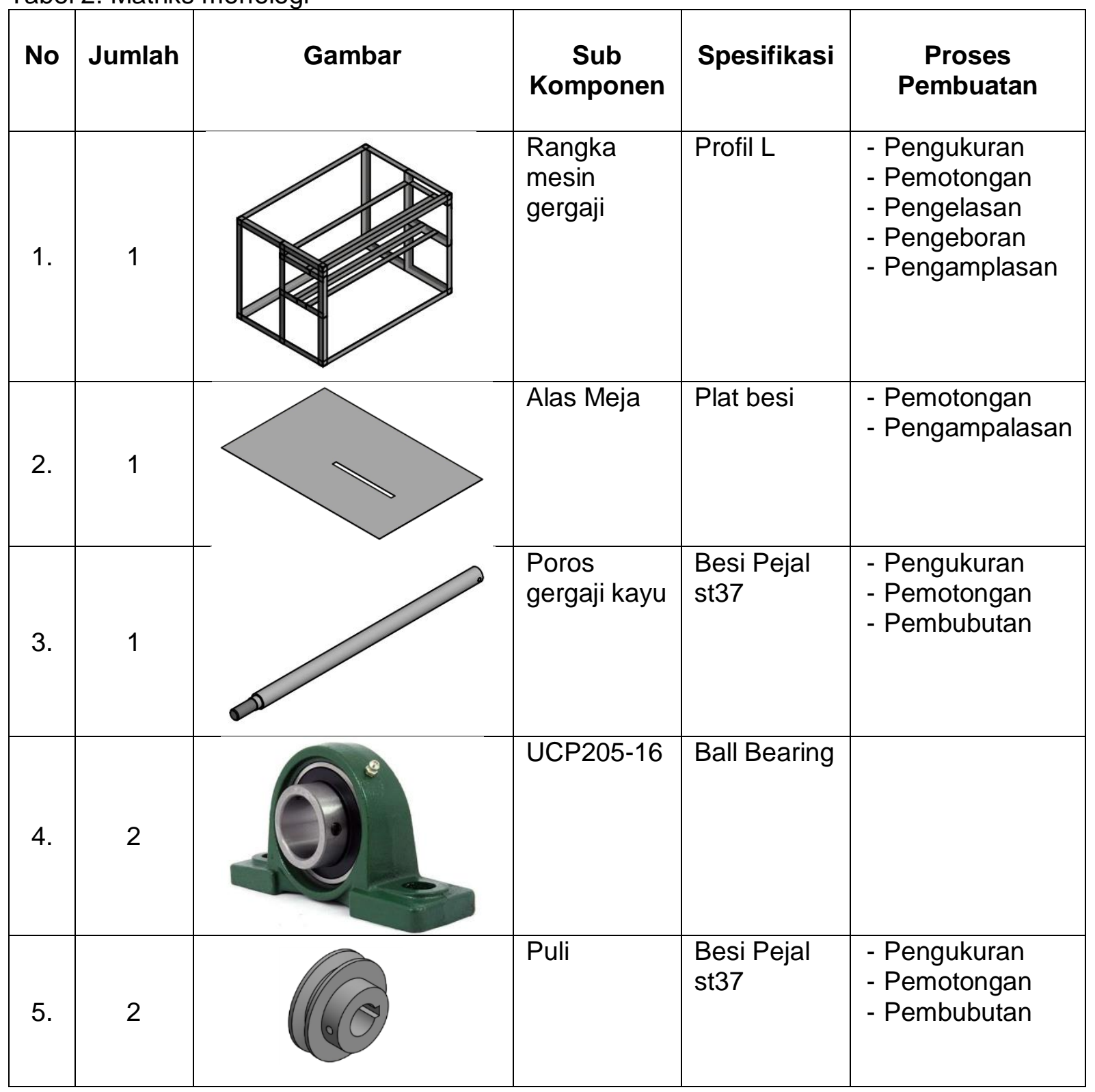




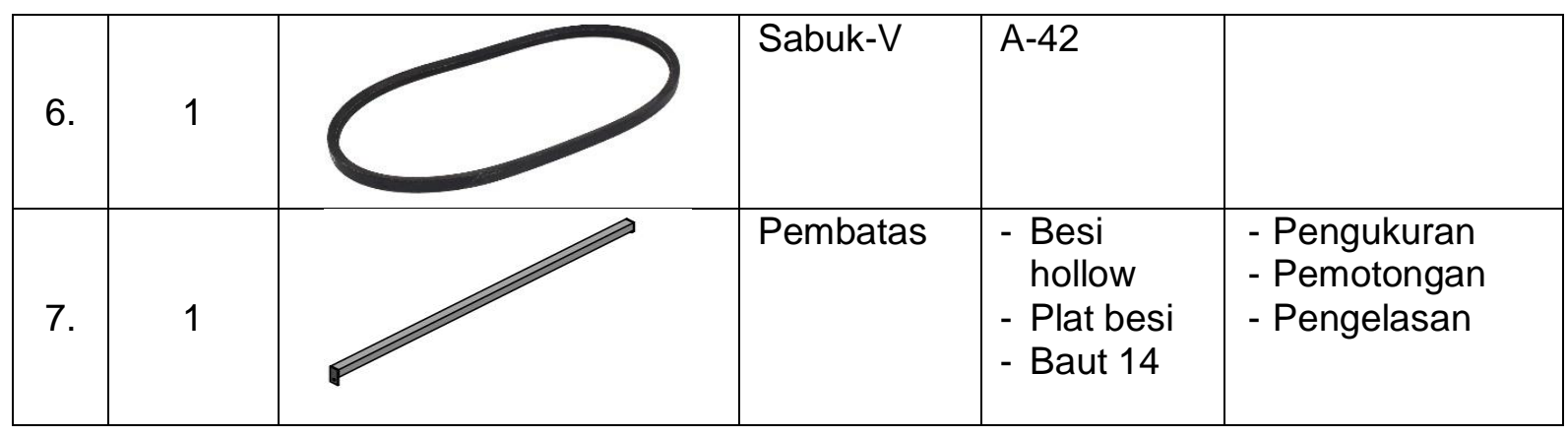

Mesin gergaji kayu yang telah di assembly bisa dilihat pada Gambar 5 .

\begin{tabular}{|c|c|l|l|}
\hline \multicolumn{4}{|c|}{ PARTS LIST } \\
\hline ITEM & QTY & \multicolumn{1}{|c|}{ PART NUMBER } & DESCRIPTION \\
\hline 1 & 1 & Frame & Equal-leg angels \\
\hline 2 & 2 & House Bearing & \\
\hline 3 & 1 & Poros & ST37 \\
\hline 4 & 1 & Pulley Gergaji & \\
\hline 5 & 2 & UCP205-16 & \\
\hline 6 & 1 & Gergaji Kayu & \\
\hline 7 & 1 & Alas & \\
\hline 8 & 1 & Motor & 2 Hp \\
\hline 9 & 1 & Pulley Motor & \\
\hline 10 & 1 & V-Belt & Type A42 \\
\hline 11 & 8 & Bolt M8 $\times 35$ & Hexagon Head Bolts \\
\hline 12 & 8 & Nut M 8 & Hexagon nuts \\
\hline 13 & 1 & Pembatas & \\
\hline
\end{tabular}

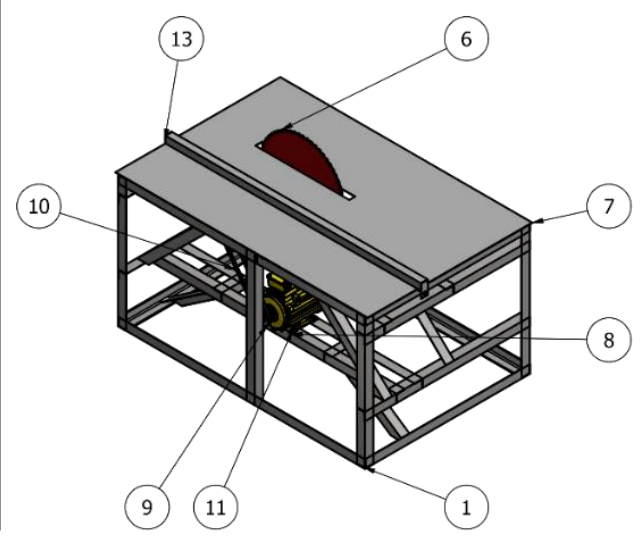

Gambar 5. Mesin Gergaji Kayu

\section{Proses Assembly}

Pada proses ini dilakukan perakitan seluruh part-part mesin gergaji kayu, yaitu:

1. Persiapan Gambar Kerja

Pertama-tama yang harus dilakukan mempersiapkan gambar kerja untuk mengetahui alat yang di buat dan dimensi ukuran alat tersebut.

2. Persiapan Alat dan Bahan

Alat yang digunakan dalam proses assembly, sebagai berikut:
a. Kunci 12 dan 14
b. Palu

Bahan yang digunakan dalam proses assembly, sebagai berikut:
a. Rangka
b. Poros
c. Bearing UCP205-16
d. Dinamo penggerak 2HP
e. Puli
f. Sabuk-v tipe A-42
g. Pisau gergaji kayu 20"
h. Baut M10
i. Baut M8
j. Alas meja
k. Pembatas

3. Berikut Proses Assembly pada mesin gergaji kayu, yaitu:

a. Pertama bearing UCP250-16 dipasang dengan rangka atas, dengan 
menggunakan baut M10.

b. Lalu poros dan bearing dipasang, kencangan pengunci dengan menggunakan kunci L.

c. Pulli dan poros dimasukkan, kencangan dengan baut M8.

d. kemudian dinamo penggerak dengan rangka bawah dengan baut M10.

e. Selanjutnya puli di dinamo penggerak dan kencangkan dengan baut M8.

f. Kemudian puli poros dan puli dinamo dengan sabuk-v ukuran A-42.

g. Selanjutnya pasang mata gergaji ke poros dan kencangkan baut menggunakan kunci 22.

h. Dan selanjutnya pasang alas meja mesin gergaji menggunakan baut M8.

i. Terakhir pasang pembatas meja mesin gergaji kayu.

j. Selesai.

\section{Perhitungan Biaya}

Perhitungan biaya mesin gergaji kayu bertujuan untuk mengetahui berapa total biaya yang di keluarkan untuk membuat mesin gergaji kayu.

\section{Biaya Bahan Baku}

Biaya yang di perlukan untuk bahan pembuatan rangka, poros, puli, alas meja, pembatas, dan bahan baku yang sudah jadi.

\section{Perhitungan Bahan Baku}

Anggaran biaya bahan baku dalam penelitian ini dapat di lihat dalam Tabel 4 . Tabel 4. Anggaran biaya bahan baku

\begin{tabular}{|c|c|c|c|c|}
\hline No. & Nama Bahan & Jumlah4 & Harga3 & Total7 \\
\hline 1. & Besi Profil L 6m & 6 & Rp.146.000,- & Rp.876.000,- \\
\hline 2. & Besi Plat $2 \mathrm{~mm}$ & 1 & Rp.600.000,- & Rp.600.000,- \\
\hline 3. & Besi Pejal st37 Ø30 mm & 1 & Rp.100.000,- & Rp.100.000,- \\
\hline 4. & Besi Pejal st37 Ø80 mm & 2 & Rp.100.000,- & Rp.200.000,- \\
\hline 5. & Dinamo Penggerak $2 \mathrm{Hp}$ & 1 & Rp.2.700.000,- & Rp.2.700.000,- \\
\hline 6. & Mata Gergaji Kayu & 18 & Rp.1.400.000,- & Rp.1.400.000,- \\
\hline 7. & Bearing UCP205-16 & 2 & Rp.50.000,- & Rp.100.000,- \\
\hline 8. & Sabuk-V A-42 & 13 & Rp.20.000,- & Rp.20.000,- \\
\hline 9. & Baut M10 & 12 & Rp.7.000,- & Rp.84.000,- \\
\hline 10. & Baut M8 & 2 & Rp.2.000,- & Rp.4.000,- \\
\hline 11. & Baut Ruping & 10 & Rp.500,- & Rp.10.000,- \\
\hline \multicolumn{4}{|c|}{ Total } & Rp.6.094.000,- \\
\hline
\end{tabular}

\section{Perhitungan Biaya Produksi}

Besar biaya yang dikeluarkan dalam proses pembuatan diasumsikan dengan biaya bermitra kerja oleh perusahaan manufaktur, biaya produksi pada proses pembuatan dapat di lihat dalam Tabel 5.

Tabel 5. Anggaran biaya produksi

\begin{tabular}{|c|l|l|l|}
\hline No. & \multicolumn{1}{|c|}{ Komponen } & \multicolumn{1}{c|}{ Jenis Alat } & \multicolumn{1}{c|}{ Total } \\
\hline 1. & Rangka mesin & $\begin{array}{l}\text { - Mesin las listrik } \\
- \text { Mesin Gerinda }\end{array}$ & Rp.300.000,- \\
\hline 2. & Alas Meja Gergaji & - Mesin Gerinda Potong & Rp.25.000,- \\
\hline 3. & Poros & $\begin{array}{l}- \text { Mesin Gerinda potong } \\
- \text { Mesin Bubut } \\
- \text { Mesin Frais }\end{array}$ & Rp.150.000,- \\
\hline 4. & Puli & - Mesin Gerinda potong & Rp.300.000,- \\
\hline
\end{tabular}




\begin{tabular}{|c|l|l|l|}
\hline & & - Mesin Bubut & \\
\hline 5. & Pembatas & $\begin{array}{l}- \text { Mesin las listrik } \\
- \text { Mesin Gerinda } \\
\text { Total }\end{array}$ & Rp.25.000,- \\
\hline \multicolumn{2}{|c|}{} & $\mathbf{R p . 8 0 0 . 0 0 0 , -}$ \\
\hline
\end{tabular}

\section{Total Biaya Pembuatan}

Total biaya pembuatan dari bahanbaku dan perlengkapan sampai biaya oprasional permesinan, adapun rinciannya sebagai berikut:
Biaya Bahan Baku
Biaya Produksi
= Rp.6.094.000,-
$=$ Rp.800.000,-
= Rp. 6.894.000,--

\section{KESIMPULAN}

Berdasarkan proses mesin gergaji kayu untuk pengrajin palet kayu, dapat diambil kesimpulan, yaitu proses manufaktur mesin gergaji kayu alat yang di gunakan adalah las listrik, mesin bubut, mesin gerinda duduk, mesin gerinda tangan, mesin bor, dan mesin frais. Komponen-komponen pada mesin gergaji yaitu rangka menggunakan besi profil $\mathrm{L}$ ketebalan $4 \mathrm{~mm}$, alas meja menggunakan plat besi ketebalan $2 \mathrm{~mm}$, dinamo penggerak 2HP, bearing UCP205-16, poros $\varnothing 25,4 \mathrm{~mm}$, transmisi puli dan sabuk $\mathrm{V}$ tipe A-42. Anggaran biaya proses manufaktur keseluruhan pada mesin gergaji kayu adalah sebesar Rp. 6.894.000,-. 


\section{DAFTAR PUSTAKA}

Aditya Eko K., 2018. "Perancangan Mesin Gergaji Kayu Untuk Pengrajin Palet Kayu" Skripsi Teknik Mesin, Universitas Lambung Mangkurat.

A. Dodong Budianto, 1995. "Mesin Tangan Industri Kayu" Edisi pertama, penerbit KANISIUS, 1995.

Daranto Drs., 1986. "Teknik Mengelas dan Kerja Pelat" Edisi pertama, Penerbit TARSITO, 1986.

Mujabirul Khoir, 2011. "Proses pembuatan spindel utama pada mesin bubut CNC" Proyek Akhir Teknik Mesin, Fakultas Teknik, Universitas Negeri Yogyakarta.

Rahdiyanta, D.D., 2010. "Proses Bubut Turning" Jurusan Pendidikan Teknik Mesin Fakultas Teknik Universitas Negeri Yogyakarta 2010.

Rian Effendi, 2018. "Proses Manufaktur Turbin Angin Sumbu Vertikal Tipe Darrieus" Skripsi Teknik Mesin, Universitas Lambung Mangkurat.

Sujiana G.N., 2016. "Proses Manufaktur Rak Benih Mesin Tanam Padi Tipe Pedal 2 Baris Model Tanam Jajar Legowo" Skripsi Teknik Mesin, Univesrsitas Lambung Mangkurat.

Suyadi, Hardi Zen, 2017. "Perhitungan Kekuatan Pisau Frais pada Proses Perautan Alur Pasak Poros Model Propeller" Balai Teknologi Hidrodinamika, BPPT, Surabaya, Indonesia.

Widarto, dkk., 2008. "Teknik Pemesinan" Editor Budi Santoso, Direktorat Jenderal Manajemen Pendidikan Dasar dan Menengah Direktorat Pembinaan Sekolah Menengah Kejuruan Departemen Pendidikan Nasional Tahun 2008. 